\title{
Correction to: COVID-19 and heme oxygenase: novel insight into the disease and potential therapies
}

\section{Philip L. Hooper ${ }^{1}$}

Published online: 29 June 2020

(C) Cell Stress Society International 2020

\section{Correction to: Cell Stress and Chaperones (2020) https://doi.org/10.1007/s12192-020-01126-9}

In the original publication, one of the last paragraphs should have read as follows:

A recent observation is that the prevalence of people who currently smoke cigarettes admitted for COVID-19 was low compared with the prevalence of smoking in the local general population. In China, of those hospitalized with Covid-19 only $6 \%$ were current smokers, whereas $27 \%$ of the general population of China smokes. (Farsalinos et al. 2020). In France, the smoker rate was 5\% of COVID-19 admissions compared with a $25 \%$ smoker rate for the general French population. (Polosa and Caci 2020).

As a result, not all citations were correct and additionally two were incomplete. The new and correct references are published below.

Farsalinos K, Barbouni A, Niaura R (2020) Systematic review of the prevalence of current smoking among hospitalized COVID-19 patients in China: could nicotine be a therapeutic option? Intern Emerg Med. https://doi.org/ 10.1007/s11739-020-02355-7

Instead of Geier and Geier (2020):

Polosa R, Caci G (2020) COVID-19: counter-intuitive data on smoking prevalence and therapeutic implications for nicotine. Intern Emerg Med. https://doi.org/10.1007/ s11739-020-02361-9

Shi S, Lei S, Tang C, Wang K, Xia Z (2019) Melatonin attenuatesacute kidney ischemia / reperfusion injury in diabetic rats by activation of the SIRT1/Nrf2/HO- 1 signaling pathway. Biosci Rep 39(1), BSR20181614. https://doi.org/10.1042/BSR20181614

Suba Z (2020) Prevention and therapy of COVID-19 via exogenous estrogen treatment for both male and female patients. J Pharm Pharm Sci 23(1), 75-85. https://doi. org/10.18433/jpps31069

Publisher's note Springer Nature remains neutral with regard to jurisdictional claims in published maps and institutional affiliations.

The online version of the original article can be found at https://doi.org/ $10.1007 / \mathrm{s} 12192-020-01126-9$

Philip L. Hooper

phoopermd@gmail.com

1 Division of Endocrinology and Metabolism, Department of Medicine, University of Colorado Anschutz Medical Campus, Aurora, CO, USA 